Article

\title{
Dynamic Water Balance Modelling for Risk Assessment and Decision Support on MAR Potential in Botswana
}

\author{
Andreas Lindhe ${ }^{1, * \mathbb{D}}$, Lars Rosén ${ }^{1}$, Per-Olof Johansson ${ }^{2}$ and Tommy Norberg ${ }^{3}$ \\ 1 Department of Architecture and Civil Engineering, Chalmers University of Technology, SE-412 96 \\ Gothenburg, Sweden; lars.rosen@chalmers.se \\ 2 Artesia Groundwater Consulting, Tunavägen 26, SE-186 41 Vallentuna, Sweden; \\ per-olof.johansson@artesia.se \\ 3 Mathematical Sciences, Chalmers University of Technology, SE-412 96 Gothenburg, Sweden; \\ sten.tommy.norberg@gmail.com \\ * Correspondence: andreas.lindhe@chalmers.se; Tel.: +46-31-772-20-60
}

Received: 20 November 2019; Accepted: 3 March 2020; Published: 6 March 2020

\begin{abstract}
Botswana experiences a water stressed situation due to the climate and a continuously increasing water demand. Managed Aquifer Recharge (MAR) is considered, among other measures, to improve the situation. To evaluate the possibility for increased water supply security, a probabilistic and dynamic water supply security model was developed. Statistically generated time series of source water availability are used in combination with the dynamic storages in dams and aquifers, and the possible supply is compared with the demand to simulate the magnitude and probability of water supply shortages. The model simulates the system and possible mitigation measures from 2013 to 2035 (23 years), using one-month time steps. The original system is not able to meet the demand, and the estimated volumetric supply reliability in the year 2035 is 0.51 . An additional surface water dam (now implemented) will increase the reliability to 0.88 but there will still be a significant water shortage problem. Implementing large-scale MAR can further improve the reliability to at least 0.95 . System properties limiting the effect of MAR are identified using the model and show how to further improve the effect of MAR. The case study results illustrate the importance and benefit of using an integrated approach, including time-dependence and future scenarios, when evaluating the need and potential of MAR.
\end{abstract}

Keywords: water supply security model; risk assessment; decision support; dynamic; probabilistic; managed aquifer recharge; integrated water resource management

\section{Introduction}

Access to potable water is essential to human health and economic development. Water scarcity and drought are, however, major challenges on all continents [1] and must thus be managed to enable safe and secure access to clean water. Climate change, increased water demand and other factors will increase the problem of water scarcity, making this a key issue to reach the UN Sustainable Development Goals [2]. This calls for integrated water resources management, including measures to avoid water losses, the efficient use of water, the introduction of water saving technologies, as well as of water re-use and recycling.

Botswana is an example where the hydrological conditions and a continuously increasing water demand result in a water stressed situation. The arid to semi-arid climate provides a situation with low rainfall and high rates of potential evapotranspiration, resulting in low rates of surface runoff and low rates of natural groundwater recharge. To enable a reliable, safe, and sustainable water supply, it is 
widely accepted that a systems approach is needed, encompassing several water resources as well as technical and other mitigation measures. Managed Aquifer Recharge (MAR) to enhance groundwater recharge and store surface water (e.g., natural water, urban storm water, treated sewage, or desalinated water) [3,4] has, in several international studies, been pointed out as an important measure to mitigate water drought and scarcity situations [5-7]. MAR has also been identified as a possible measure to be implemented in Botswana [8,9]. However, to properly evaluate if MAR is a suitable option and the benefits it may provide, a holistic system analysis considering both current and future conditions is needed. Not only the potential storage and other aquifer specific properties should be determined, but also the reliability and access to water over time must be analysed in detail, considering risks and variations in water demand and supply. Hence, a risk-based approach is needed to provide decision support on water supply security and the effect of MAR. Water security is defined in different ways in the literature [10-12] but typically includes the water quantity aspect, which is the focus of this paper.

Different methods for selecting suitable sites for MAR exist and are typically based on GIS [13-15]. When designing the final MAR scheme and determining operational strategies etc., a detailed groundwater model is commonly used [16]. No generically accepted method exists, however, for assessing the overall effect of MAR on the water supply security. Several examples exist where system dynamic modelling [17] has been used to analyse the conjunctive use of surface water and groundwater. This approach is common when evaluating policy options [18,19] but examples including aquifer storage and recover exist [20]. Another type of modelling approach was applied by Clark et al. [21] to analyse the reliability of water supply from stormwater harvesting and MAR. A model combining stormwater hydrology with subsurface storage and demand was used and repeated simulations were performed to estimate the volumetric reliability. Gao et al. [22] analysed the reliability of an urban water supply using Monte Carlo analysis to model variations in surface water availability. Aquifer injection and banking was analysed with the aim to identify the most cost-effective way to meet specified criteria for supply reliability. These examples show the importance of creating models that include the entire system to be analysed and to compare the possible supply and water demand so that mitigation measures' effect on water security can be estimated.

An integrated and holistic approach is important to avoid overlooking interactions between subsystems and events, and to minimise the sub-optimisation of mitigation measures [23]. The importance of considering the entire supply system when assessing drinking water risks is emphasised by, for example, the World Health Organization (WHO) as part of a framework including Water Safety Plans (WSPs) [24]. A WSP is typically focused on water quality but the integrated approach is equally applicable to water supply security.

In this paper, a Water Supply Security Model (WSSM) is presented and applied to assess risks in the main drinking water supply in Botswana and to evaluate and provide decision support on the potential effects of MAR. The overall aim of the work was to enable a holistic assessment of the potential for using large-scale MAR to improve the water supply security in Botswana. The specific objectives were to (i) develop a comprehensive and dynamic water balance model, (ii) simulate and show the predicted water shortage over time, and (iii) model the potential of alternative mitigation measures and identify limiting factors.

\section{Study Area}

Botswana is located in south-central Africa and occupies an area of approximately $582,000 \mathrm{~km}^{2}$. The total population of the nation is a little over 2 million, making Botswana one of the most sparsely populated countries in the world. The country is predominantly flat with some parts having a slightly rolling landscape. Botswana is dominated by the Kalahari Desert, covering about $70 \%$ of the total area. The north-east part of Botswana has an annual precipitation of about $600 \mathrm{~mm}$, whereas the drier south-west receives, on average, only $200 \mathrm{~mm}$ per year. Due to the arid to semi-arid climate, potential evapotranspiration rates exceed the total rainfall at all times of the year [8]. There are no perennial streams originating in Botswana. It is estimated that the mean annual rates of surface runoff do not 
exceed $50 \mathrm{~mm}$ anywhere except in small steep rocky catchments. The annual recharge to aquifers from rainfall reaches a maximum of about $40 \mathrm{~mm}$ in small areas in the Chobe District in the north. For most of the Kalahari region, the natural groundwater recharge is less than $1 \mathrm{~mm} /$ year [8]. The largest groundwater resources are in the Kalahari sediments (including the Okavango Delta), the Ntane Sandstone, the Ecca Sandstones, and the Damaran and Ghanzi rock formations.

In eastern and southern Botswana, with its relatively high density of population and substantial water demand, several surface water dams have been constructed to collect and store ephemeral river flow. The largest dams are the Shashe, Dikgatlhong, Letsibogo, and Gaborone dams. The storages of the dams are very variable due to the highly seasonal, occasional, and variable river flows. In addition, the need to store water for drought periods and the flat topography in most areas result in large losses of water to evaporation from these dams. The surface water dams in eastern Botswana have been connected through a nearly 400-km long pipeline transfer system denoted the North-South Carrier (NSC), providing possibilities to transfer water to urban centres.

The NSC water supply system is the focus of this study and the included demand centres, surface water dams, aquifers and additional components are shown in Figure 1. The study was performed in the year 2013 and the descriptions of the system, planned measures, etc., are thus based on the situation at that time. The Dikgatlhong Dam was being constructed when the study was performed and thus included in one of the modelled scenarios to represent the coming system structure. In addition to the surface water dams, a few groundwater wellfields are connected or are planned to be connected to demand centres supplied with water from the NSC, e.g., Palla Road, Chepete, Masama, Makhujwane, Malotwane, and Palapye Wellfields.

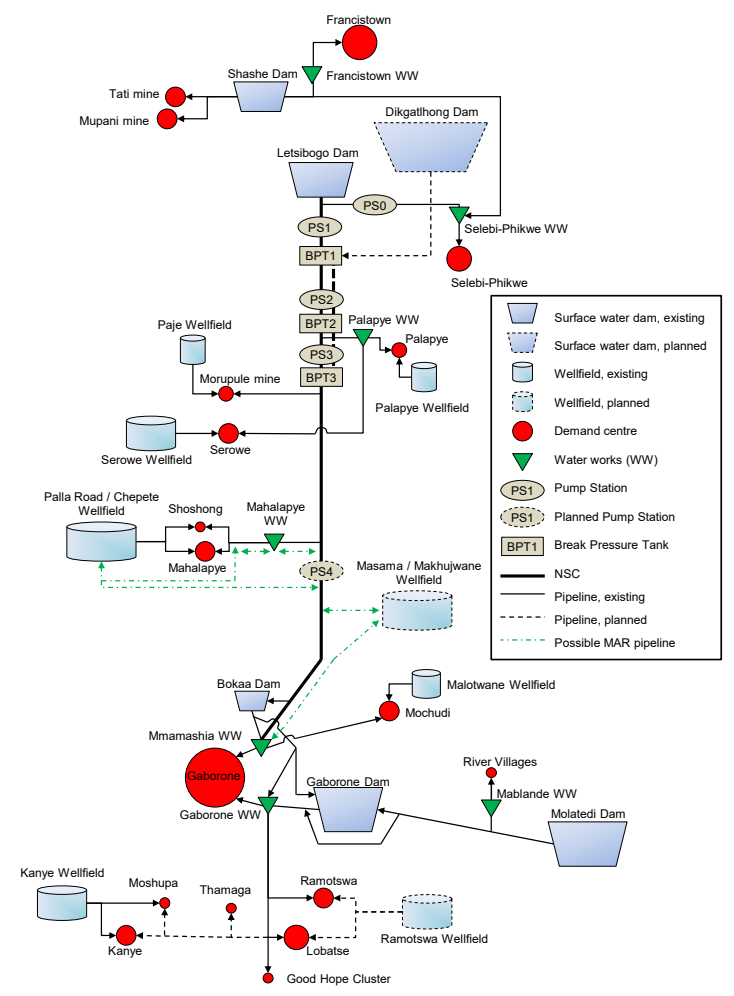

Figure 1. Schematic illustration of the water supply system linked to the North-South Carrier (NSC), according to the situation when the study was performed in the year 2013.

Due to the highly variable storage in surface water dams, the groundwater aquifers have a potential to support the NSC demand centres during drought periods. Because of the very limited natural recharge to these aquifers, their long-term sustainable capacity could be improved by managed recharge with surface water. Managed recharge (injection) with collected and treated surface water from dams may also reduce the total loss of water to evaporation. The focus of the case study is thus to 
evaluate the possibility and effects on the water supply security of MAR scenarios including the Palla Road/Chepete and Masama/Makhujwane Wellfields.

\section{Materials and Methods}

\subsection{Water Supply Security Model (WSSM)}

The WSSM is a dynamic water balance model where statistically generated time series of the availability of source water are used, together with dynamic storages in dams and aquifers, as well as water demands, to simulate the magnitude and probability of water supply shortages. Models have been previously developed for the water supply in Botswana but they have not considered MAR scenarios [8]. The WSSM is developed as a spreadsheet model in Excel since one of the goals of this study was to provide an easily accessible model that can be run without expert knowledge. To enable statistical analysis considering uncertainties in input data and results, an add-in software (Oracle (RCrystal Ball) is used to run Monte Carlo simulations.

The WSSM simulates the NSC system and connected components from 2013 to 2035 (23 years). The period is selected to match water demand forecast in the National Water Master Plan Review [8]. The simulations are performed with a time step of one month and for each month the demand, the available storage in dams and aquifers, as well as treatment capacities, water losses, etc., are considered.

The schematic illustration in Figure 2 shows the parameters considered in the model and the link to the model components. Based on historical data on inflow to the dams (see Section 3.2), a set of possible time series are generated and used to sample from when running the model. The generated time series consider the correlation between the dams and each generated data set includes all five dams. The annual inflow data is transformed into monthly data based on the closest historical annual inflow and the monthly distribution that year. Since the dams are spatially correlated, the historical data for the Gaborone Dam is used when transforming the simulated annual data for the Bokaa and Gaborone Dams. In the same way, the historical data for the Dikgatlhong Dam is used for the Letsibogo, Shashe, and Dikgatlhong dams.

For each dam, water balance calculations are performed for each month, considering initial storage, inflow, abstraction, evaporation, seepage, spill over, and additional parameters presented in Figure 2. The input data is based on [8] and information from personnel at the Water Utility Corporation (WUC) and the Department of Water Affairs (DWA). The evaporation is calculated based on the area-storage relationship and data from previous studies in the area [8,25]. Key inputs for modelling the dams in the WSSM are presented in Table 1.

Table 1. Storage properties and environmental flows for the dams included in the Water Supply Security Model (WSSM).

\begin{tabular}{|c|c|c|c|c|c|}
\hline Dam Property & Gaborone & Bokaa & Letsibogo & Dikgatlhong & Shashe \\
\hline Maximum storage $\left(\mathrm{Mm}^{3}\right)$ & 140.59 & 18.20 & 108.00 & 397.60 & 75.05 \\
\hline $\begin{array}{l}\text { Minimum operational storage }(\% \text { of } \\
\text { max storage) }\end{array}$ & 15 & 3 & 5 & 4 & 15 \\
\hline Initial storage, 1 Jan $2013\left(\mathrm{Mm}^{3}\right)$ & 49.65 & 7.08 & 31.00 & 198.80 & 59.62 \\
\hline Seepage $(\mathrm{L} / \mathrm{s})$ & 0.0 & 0.0 & 0.0 & 30.0 & 0.8 \\
\hline Environmental flow, Feb; Nov & $0 ; 0$ * & $0 ; 0$ * & $2.49 ; 0.49 * *$ & $5 ; 5^{*}$ & $0 ; 0$ * \\
\hline $\begin{array}{l}\text { Loss due to sedimentation } \\
\left(\mathrm{Mm}^{3} / \text { year }\right)\end{array}$ & 0.22 & 0.04 & 0.35 & 0.70 & 0.61 \\
\hline
\end{tabular}




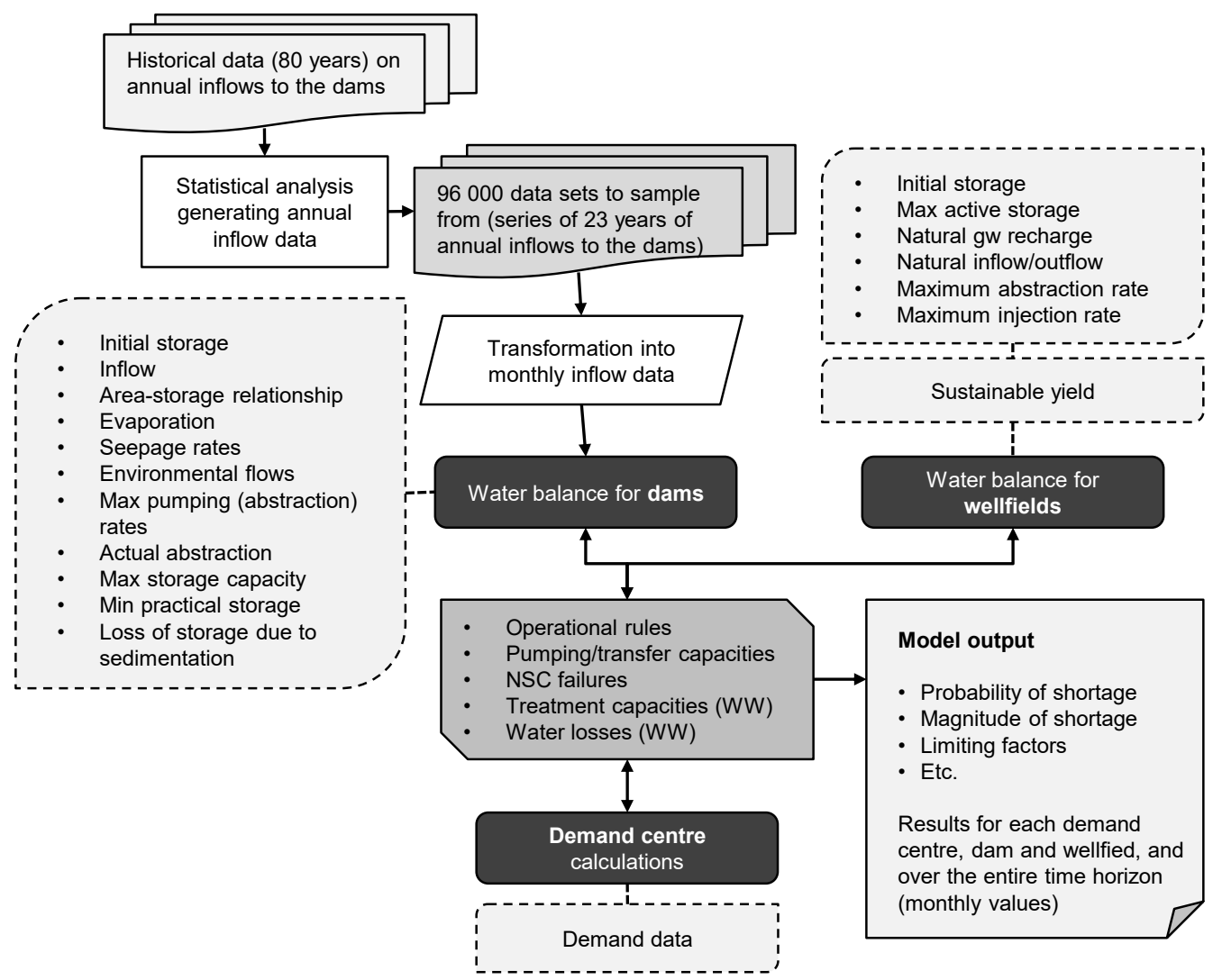

Figure 2. Overview of the parameters considered in the model and the link between them.

The water balance calculations for MAR wellfields are performed considering initial storage, natural recharge, inflow, injection, outflow, and abstraction. Necessary input data for the aquifers are based on [26-29], and the key figures used in the scenarios modelled here (see Section 3.3) are presented in Table 2 . The wellfields are recharged by injecting water if the maximum storage is not reached and provided that water is available in the dams and is at a capacity to abstract, treat, transfer, and inject the water. A critical dam storage level (20\%) was defined by the WUC and DWA and is used as an operational rule in the model stating that water for injection may only be abstracted when the dam storage is above this level. The abstraction of water from the MAR wellfields starts when the water demand cannot be met by the supply of treated surface water and the non-MAR wellfields. The abstraction is only limited by the abstraction rate and capacity to treat and distribute the water.

Table 2. Input data on Managed Aquifer Recharge (MAR) wellfields to the WSSM.

\begin{tabular}{ccc}
\hline Wellfield Property & Palla Road/Chepete & Masama/Makhujuwane \\
\hline Maximum active storage & 42.8 & 40.0 \\
Initial storage $\left(\mathrm{Mm}^{3}\right)$ & 40.5 & 40.0 \\
Natural groundwater & 12,383 & 3379 \\
recharge $\left(\mathrm{m}^{3} / \mathrm{d}\right)$ & 0 & 0 \\
Groundwater inflow $\left(\mathrm{m}^{3} / \mathrm{d}\right)$ & $7600-12,000$ (function of & $0-3600$ (function of active storage) \\
Groundwater outflow $\left(\mathrm{m}^{3} / \mathrm{d}\right)$ & active storage) & 37,734 \\
Maximum abstraction and & 21,342 & \\
injection rates $\left(\mathrm{m}^{3} / \mathrm{d}\right)$ & &
\end{tabular}

For the wellfields not considered relevant for MAR, an estimated sustainable yield is used as a maximum abstraction rate to not cause groundwater mining. The sustainable yield is estimated on an annual basis and defined in the model as a monthly maximum abstraction that may not be exceeded. 
The total sustainable yield for the non-MAR wellfields is $7.2 \mathrm{Mm}^{3}$, and $11.7 \mathrm{Mm}^{3}$ when also including the Masama/Makhujuwane and Palla Road/Chepete Wellfields as non-MAR wellfields.

The water demand forecast from [8] is used to determine how much water must be abstracted from the dams and wellfields. The estimated change in water demand is based on a population forecast and an increase in specific water demand, including assumptions of changes from standpipe to yard and yard to house connections. The assumed industrial, commercial, and institutional annual growth rate is 3\%. Unaccounted-for water, including technical losses and non-technical losses (unmetered consumption and illegal connections), is also considered in the forecast. Since the reported water consumption in 2012 was $4 \mathrm{Mm}^{3}$ /year lower than the forecast for the same year, the original demand forecast was reduced by this volume. The total annual demand for the demand centres included in the WSSM is $81 \mathrm{Mm}^{3}$ in 2013 and $148 \mathrm{Mm}^{3}$ in 2035.

In addition to the capacities and other parameters presented above, a set of operational rules are used to determine, for example, when different sources are used and to what demand centres and the extent to which water is supplied. In all calculation steps, available abstraction rates, treatment capacities, water losses during treatment etc., are considered. The model is thus not used to optimize the supply from different sources but to estimate the performance based on the actual operational rules used to manage the system. The schematic illustration in Figure 1 shows how the different components of the system are connected and how water can be transferred. The actual supplied amount of water is compared with the demand for each demand centre and possible shortage etc., is calculated in each time step.

\subsection{Dam Inflow Time Series}

The time series of monthly inflows to the five dams (Gaborone, Bokaa, Letsibogo, Dikgatlhong and Shashe) are available based on measurements and hydrological modelling for the 80-year period of 1925 to 2004 [8] (vol. 11). The dams are grouped based on their spatial correlation and the annual inflows are presented in Figure 3. An analysis of the annual inflows is made to generate 96,000 future annual inflow time series ( 23 years) that are used to sample from when running the WSSM. This five-dimensional time series is modelled as a first-order stationary Gaussian Auto-Regressive, $\mathrm{AR}(1)$ sequence:

$$
y_{t}-\mu=\Phi\left(y_{t-1}-\mu\right)+\varepsilon_{t}
$$

where the column vector $y_{t}$ is the annual inflow and $t=-79,-78, \ldots, 0(t=0$ corresponds to year 2004). The column vectors $\mu$ and $\varepsilon_{t}$ denote the long-time yearly mean and white noise, respectively, the latter with covariance matrix $\Sigma$. To carry out a standard least squares (LS) estimation, the model is rewritten as follows:

$$
y_{t}=\Phi y_{t-1}+b+\varepsilon_{t}
$$

where $b=(I-\Phi) \mu$ (I denotes the identity). The model parameters $\Phi, b$, and $\Sigma$ are estimated by the method of least squares. $\Phi$ is a 5 by 5 coefficient matrix and $y, b$ and $\varepsilon_{t}$ are 5 -dimensional column vectors. Also estimated is the spatial covariance matrix:

$$
\gamma=E\left(y_{t}-\mu\right)\left(y_{t}-\mu\right)^{\prime}
$$

where the prime' denotes transpose. Future dam inflow values $y_{1}, y_{2}, \ldots, y_{23}$ are then repeatedly simulated from the estimated model, taking the uncertainty of the LS estimates into account. 
(a)

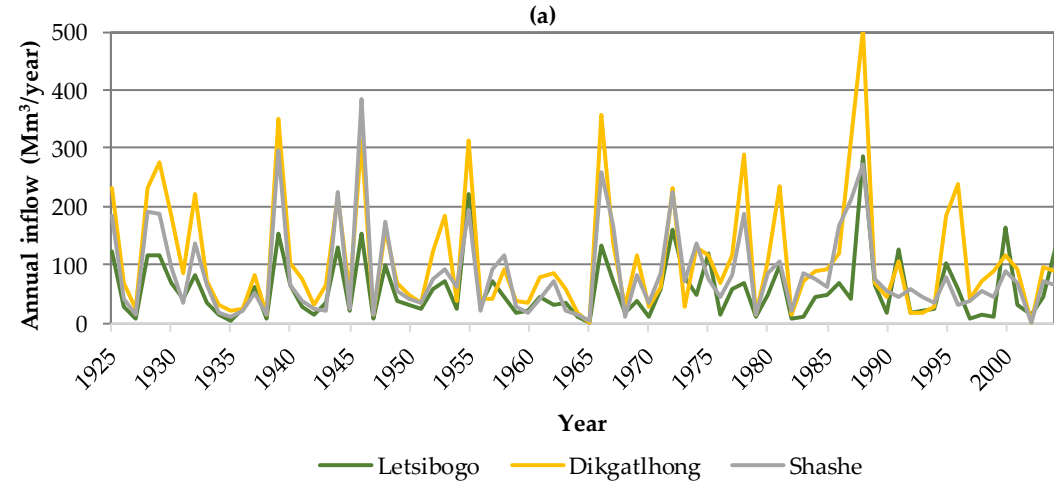

(b)

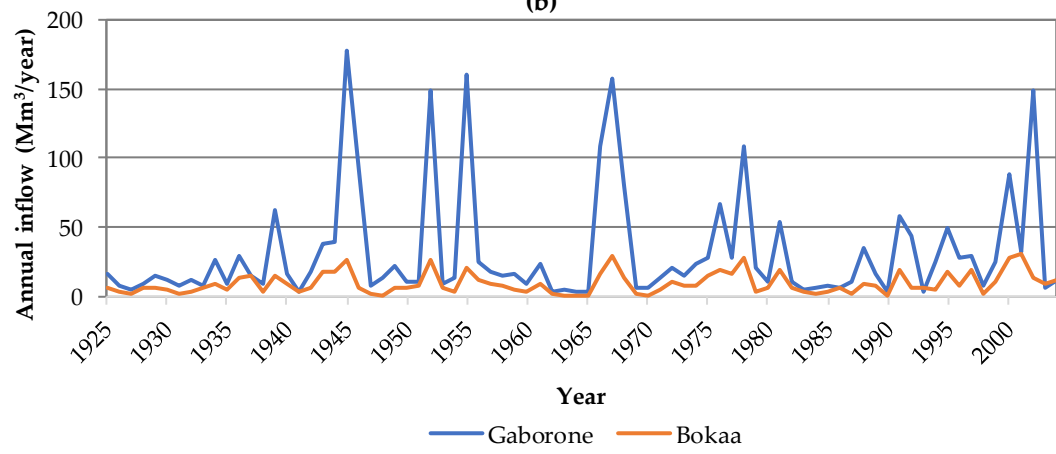

Figure 3. Historic inflow time series (80 years, 1925-2004) for the dam sites: (a) Letsibogo, Dikgatlhong and Shashe; (b) Gaborone and Bokaa [8].

\subsection{Scenarios}

The system included in the analysis and implemented in the WSSM includes: 6 surface water dams, 8 wellfields, 7 water works, and 18 demand centres. In addition to five dams previously presented, the Molatedi Dam in South Africa is also included in the model. A constant supply $(80 \%$ of the maximum agreed transfer) from the dam is assumed since no historical time series are available. The same assumption has previously been used when evaluating the supply system [8]. The selection of wellfields for MAR scenarios was based on [9,26-33] and workshops including representatives from the DWA, WUC, and the authors. Several scenarios including MAR and non-MAR wellfields are possible, but we here focus on the three scenarios listed below as a basis for evaluating the potential of using large scale MAR in Botswana. The system structure in 2013 (Scenario A), i.e., when the study was performed, is used as a reference to illustrate the need and potential effects of mitigation measures (Scenarios B and C) on the water supply security. As mentioned above, the Dikgatlhong Dam was under construction when the study was performed and is now in operation. Hence, the dam is included in Scenario B and combined with MAR in Scenario C. The purpose is not to evaluate MAR as an alternative measure to the Dikgatlhong Dam but to see how MAR can further improve the system. To facilitate a relative comparison of the mitigation measures, i.e., the Dikgatlhong Dam and the MAR wellfields, they are included from the start of the simulated period (i.e., year 1).

A. Current system (as in year 2013)

B. Current system + Dikgatlhong Dam (implemented after the study)

C. Current system + Dikgatlhong Dam + Palla Road/Chepete Wellfields MAR + Masama/ Makhujwane Wellfields MAR 


\section{Results}

The results from the WSSM show that the supply system in Scenario A is clearly insufficient to meet the water demand within the simulated period of 23 years. Water shortage is likely to be a problem early in the simulated period and is expected in around 70\% (mean value) of the months for most demand centres. Given a month with water shortage, the deficit varies between c. 20-60\% of the demand. The water supply security can be assessed based on the volumetric reliability, i.e., the volume of water supplied divided by the demand in a given year. The results are presented in Figure 4 and show that the reliability is dramatically reduced for Scenario A over the simulated period. There is no reliability target level defined in Botswana but at the end of the simulated period the level is only 0.51 (mean value). As a comparison, case studies in Australia [21,22] have applied a 0.995 volumetric reliability target for potable supplies and a 0.95 target level for non-potable use.

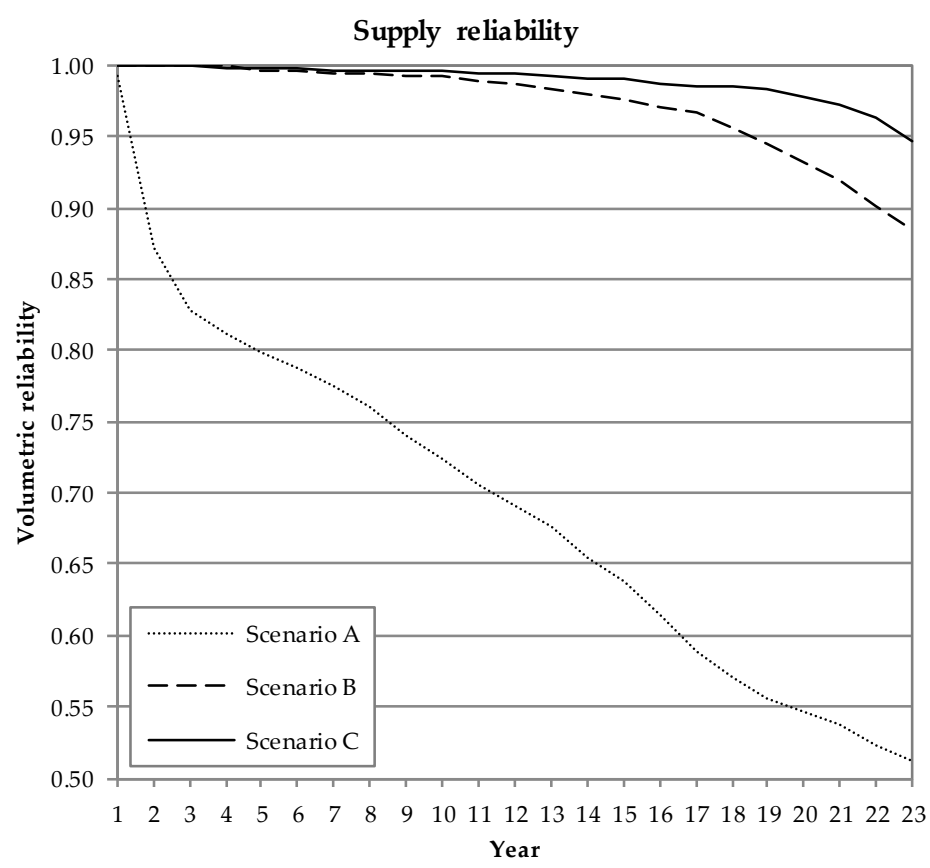

Figure 4. Annual volumetric reliability (mean value) of the supply to Great Gaborone over the simulated period (23 years).

In Figure 5, the expected (mean) probability of annual water shortage of different magnitudes is presented for Gaborone and the demand centres connected to the capital city, here referred to as Great Gaborone. The results are similar for most of the demand centres, and, for evaluating the potential effect of MAR, we focus on Great Gaborone. The total demand for Great Gaborone will increase over the analysed period from 44.8 (year 2013) to $82.4 \mathrm{Mm}^{3} /$ year (year 2035). The water demand for Great Gaborone constitutes $62 \%$ of the total demand in the NSC system.

The connection of the Dikgatlhong Dam to the NSC and the related system upgrades (Scenario B) will have a large positive effect on the supply security, see Figure 6, and reduce the expected total water shortage (summed over the 23 years) by approximately $90 \%$. The supply reliability will increase (Figure 4) and be $>0.99$ for approximately 10 years. However, in 2035, the reliability is estimated to be 0.88 and the results thus show that there still will be a significant risk for water shortage for Great Gaborone during the late part of the simulation period. 


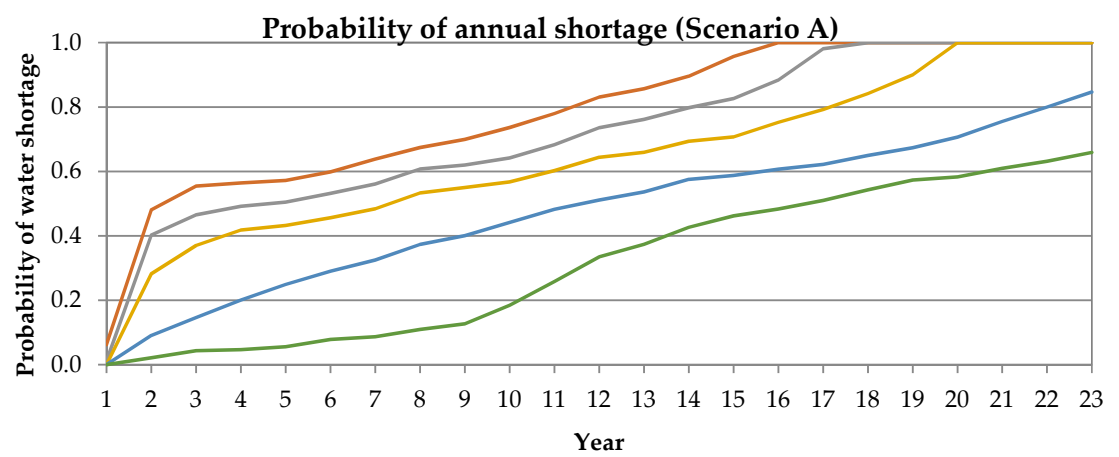

Figure 5. Expected probability of annual water shortages of different magnitudes in Great Gaborone for each year in Scenario A.

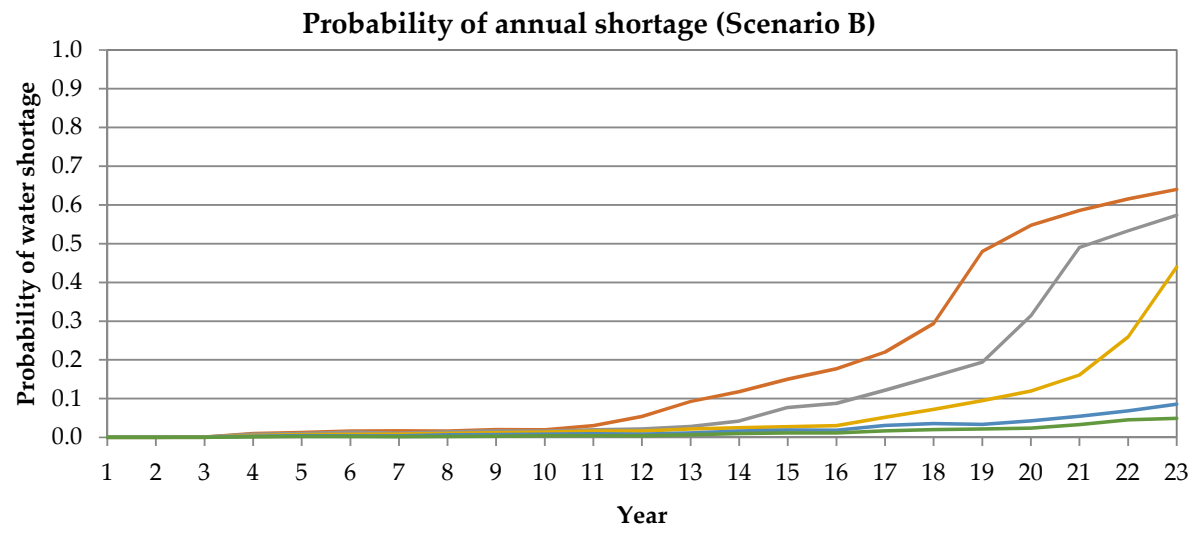

Figure 6. Expected probability of annual water shortages of different magnitudes in Great Gaborone for each year in Scenario B, including the Dikgatlhong Dam.

In Figure 7, the results are presented for Scenario C, i.e., including the MAR wellfields. The probability of shortage is further reduced compared to Scenario B. For example, the probability of having a $10 \%\left(8 \mathrm{Mm}^{3}\right)$ water shortage in Great Gaborone in 2035 is reduced from $40 \%$ (Scenario B) to $10 \%$. For Scenario C, the supply reliability is $>0.99$ in approximately 15 years and is estimated to be 0.95 in 2035. The effects of implementing MAR are, however, limited due to the capacity of different system components. As an example, Figure 8 shows what limiting the injection of water from the dams at the Palla Road Wellfield. Injection is expected to be needed in $41 \%$ of the months. In $34 \%$ of these months, injection up to the full storage or maximum injection rate is obtained. However, the dam storage (abstraction of water for injection only allowed if dam storage is $>20 \%$ ), the abstraction rate from dams, and the capacity of the treatment plants (only treated water is injected) are limiting the injection in $45 \%, 17 \%$, and $4 \%$ of the cases, respectively. If the most critical technical system properties causing the limitations are eliminated, the positive effects of MAR in Scenario C further increase. For example, the supply reliability in 2035 will increase to 0.97 and the probability of an annual water deficit of $2 \mathrm{Mm}^{3}$ ( $2.5 \%$ of the demand) will reduce from $32 \%$ to $10 \%$. This effect can be obtained without any substantial risk of mining the wellfields. The maximum active storage for the Masama/Makhujwane and Palla Road/Chepete Wellfields are 40 and $42.8 \mathrm{Mm}^{3}$, respectively (Table 2). The probability of having full storage at the end of the simulated period is 0.8 for both wellfields in Scenario $C$ when the key limiting factors have been eliminated. If the limitations are included, the probability of full storage is 0.2 and 0.5 , respectively. 


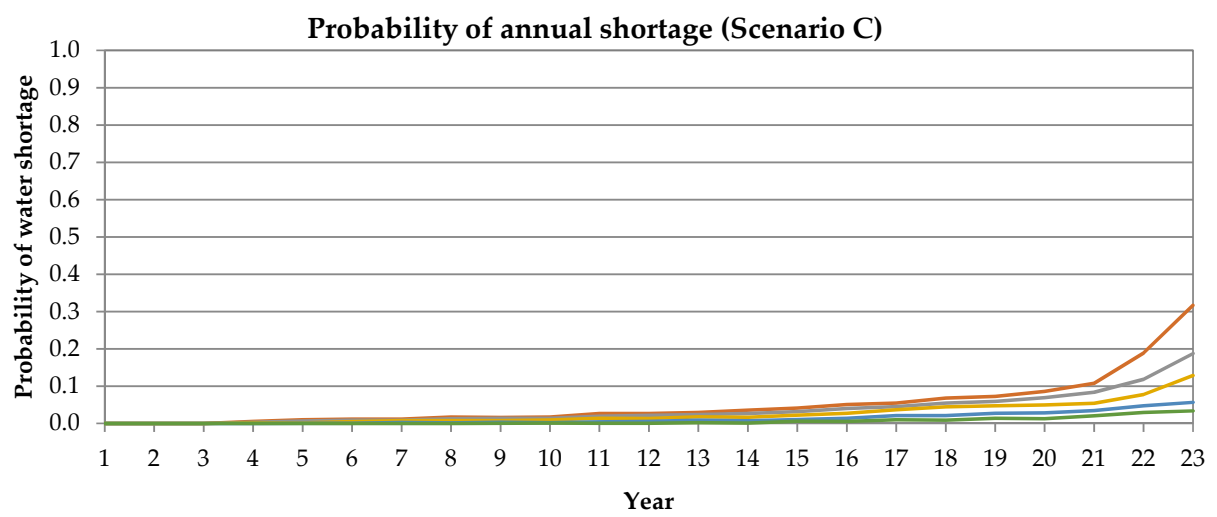

Figure 7. Expected probability of annual water shortages of different magnitudes in Great Gaborone for each year in Scenario C, including Masama/Makhujwane and Palla Road/Chepete, MAR.

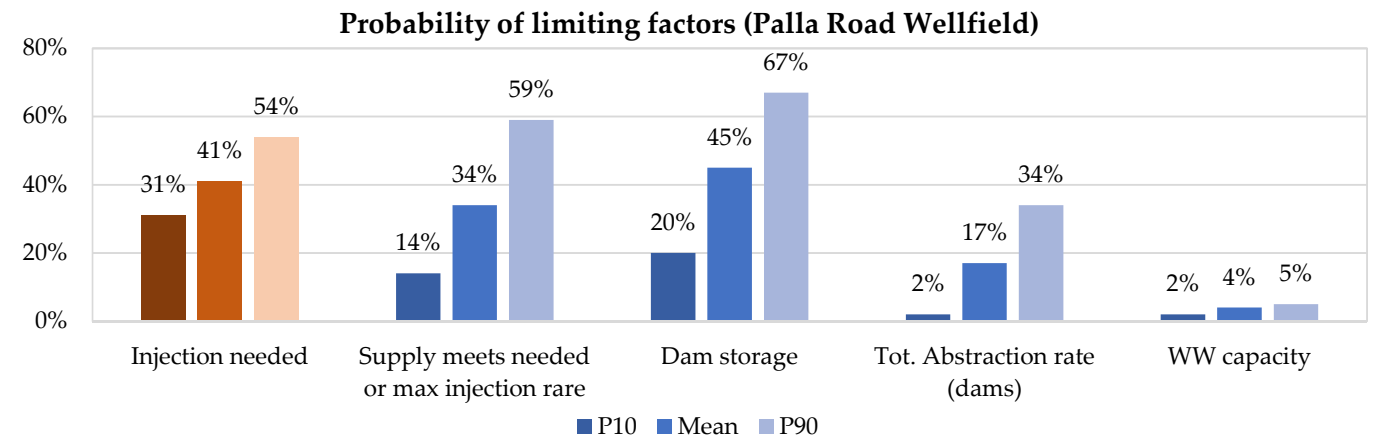

Figure 8. Factors limiting the injection at Palla Road Wellfield, Scenario C.

Provided that no water is abstracted and the maximum injection can be applied, it would take 5-6 years to recharge the MAR wellfield from $0 \mathrm{Mm}^{3}$ to full storage. If dependent on natural groundwater recharge only, the wellfields will only be recharged up to approximate half of the maximum storage after the simulated 23 years.

\section{Discussion and Conclusions.}

The performed case study addresses the possible effects of implementing MAR in the NSC system in Botswana. It is concluded that the NSC system including the Dikgatlhong Dam (Scenario B) but without MAR is not likely to be able to provide a safe water supply over the entire time period. When the water demand increases, the reliability of the system is reduced. Implementing MAR at the Palla Road/Chepete and Masama/Makhujwane Wellfields (Scenario C) will further improve the system, although not eliminate the risk of future water shortage. However, implementation of MAR may be of great importance in managing the water supply situation in eastern Botswana.

By including the Dikgatlhong Dam in the system (Scenario B), an additional water source is added and the potential volume of water that may be accessible is increased. Due to the spatial correlation between the dams, periods of no or limited inflow may affect several dams at the same time and thus cause a severe water shortage. By including the MAR wellfields, we add components that are dependent on the surface water dams to be recharged but the water stored in the aquifers can be used independently of the dams. The latter part is one of the key reasons for the increased reliability in Scenario $C$. The results show that over time there is enough water in the dams to be able to recharge the MAR wellfields. However, the possibility to inject water is partly limited in Scenario C due to both the capacity of the system components and access to the surface water. If these limitations are reduced or eliminated, the positive effect of implementing MAR will further increase.

The non-MAR wellfields are operated using the estimated sustainable yields as a maximum monthly abstraction rate. If this criterion would have been defined on an annual basis and allowed a 
varying abstraction over the year, it is possible that some smaller shortage events could have been avoided. Another criterion for sustainable yield could be implemented into the WSSM but would, however, not have a significant effect on the more severe shortage events. By allowing the same abstraction rates for the Palla Road/Chepete and Masama/Makhujwane Wellfields, as in Scenario C, but without MAR, the system would improve but only for a limited time. Due to the limited natural groundwater recharge, the aquifers would gradually be emptied. MAR is thus needed in order to provide for a long-term sustainable solution.

The results from the modelled scenarios do not show any cases where the implementation of MAR reduces the supply system security in Botswana. This could be the case if, for example, there are large losses of water or the abstraction rate is too low compared to the surface water dams.

The developed WSSM enables a thorough analysis and evaluation of the original system as well as the effect of both MAR implementation and other system changes. A key advantage of the model is the ability to not only model the possible enhanced groundwater recharge over time but to compare the possible supply and demand for all system components. The predicted water shortage over time in combination with dam and groundwater levels provides a comprehensive picture of the system performance. This makes it possible to evaluate system reliability with consideration to the entire system and compare MAR scenarios with other possible measures to avoid the sub-optimisation of risk mitigation measures.

Furthermore, system properties limiting the effects of MAR can be identified as shown in the case study. This result can guide further analysis and improvements to enhance the effect of implementing MAR. Hence, the WSSM can provide results to support decisions on both larger system changes and minor upgrading to improve water supply security.

The main conclusions of this study are:

- The developed WSSM is a comprehensive and dynamic water balance model that enables a thorough analysis of recharge and abstraction from MAR wellfields as well as the overall system reliability.

- The case study application demonstrates the practical applicability of the model and shows that useful decision support is provided.

- Future development of the WSSM approach will include consideration to climate change in dam inflow data and other relevant system parameters.

- $\quad$ The WSSM provides added value by enabling an integrated approach, including time-dependence and future scenarios, when evaluating the need and potential of implementing MAR.

Author Contributions: The study was initiated by all authors. L.R. was the project leader and P.-O.J. analysed and estimated input data related to aquifers and water demand. A.L. created the water supply security model with support from the other authors. T.N. analysed and modelled time series of inflows to surface water dams. A.L. performed the calculations and was the main author of the paper. All authors have read and agreed to the published version of the manuscript.

Funding: This research was funded by the Swedish International Development Cooperation Agency (Sida) and the Botswana Department of Water Affairs (DWA).

Acknowledgments: The authors gratefully acknowledge the contributions of the DWA and the Water Utility Corporation (WUC) in Botswana.

Conflicts of Interest: The authors declare no conflict of interest.

\section{References}

1. UN WATER-Water Scarcity. Available online: http://www.unwater.org/water-facts/scarcity/ (accessed on 26 February 2019).

2. UN Sustainable Development Goals. Available online: https://www.un.org/sustainabledevelopment/ (accessed on 26 February 2019). 
3. Dillon, P.; Arshad, M. Managed aquifer recharge in integrated water resource management. In Integrated Groundwater Management: Concepts, Approaches and Challenges; Jakeman, A.J., Barreteau, O., Hunt, R.J., Rinaudo, J.-D., Ross, A., Eds.; Springer International Publishing: Cham, Switzerland, 2016; pp. 435-452.

4. Maliva, R.; Missimer, T. Overview and impacts on arid land water resources. In Arid Lands Water Evaluation and Management; Springer Berlin Heidelberg: Berlin/Heidelberg, Germany, 2012; pp. 975-999.

5. Murray, R.; Tredoux, G.; Ravenscroft, P.; Botha, F. Artificial Recharge Strategy; Version 1.3; Department of Water Affairs and Forestry \& Water Research Commission: Pretoria, South Africa, June 2007.

6. Murray, E.C.; Tredoux, G. Artificial Recharge: A Technology for Sustainable Water Resource Development; Report No 842/1/98; Water Research Commission: Pretoria, South Africa, 1998.

7. Dillon, P.; Stuyfzand, P.; Grischek, T.; Lluria, M.; Pyne, R.D.G.; Jain, R.C.; Bear, J.; Schwarz, J.; Wang, W.; Fernandez, E.; et al. Sixty years of global progress in managed aquifer recharge. Hydrogeol. J. 2019, 27, 1-30. [CrossRef]

8. Department of Water Affairs. National Water Master Plan. Review; Ministry of Minerals, Energy \& Water Resources, Government of Botswana: Gaborone, Botswana, 2006.

9. Groundwater Africa. Managed Aquifer Recharge (MAR): Support to the Department of Water Affairs, Botswana, Final report; Groundwater Africa: Somerset West, South Africa, 2012.

10. Grey, D.; Sadoff, C.W. Sink or Swim? Water security for growth and development. Water Policy 2007, 9, 545-571. [CrossRef]

11. Cook, C.; Bakker, K. Water security: Debating an emerging paradigm. Glob. Environ. Chang. 2012, 22, 94-102. [CrossRef]

12. Gerlak, A.K.; House-Peters, L.; Varady, R.G.; Albrecht, T.; Zúñiga-Terán, A.; de Grenade, R.R.; Cook, C.; Scott, C.A. Water security: A review of place-based research. Environ. Sci. Policy 2018, 82, 79-89. [CrossRef]

13. Rahman, M.A.; Rusteberg, B.; Gogu, R.C.; Lobo Ferreira, J.P.; Sauter, M. A new spatial multi-criteria decision support tool for site selection for implementation of managed aquifer recharge. J. Environ. Manag. 2012, 99, 61-75. [CrossRef] [PubMed]

14. Russo, T.A.; Fisher, A.T.; Lockwood, B.S. Assessment of managed aquifer recharge site suitability using a GIS and modeling. Groundwater 2015, 53, 389-400. [CrossRef] [PubMed]

15. Sallwey, J.; Schlick, R.; Bonilla Valverde, J.P.; Junghanns, R.; Vásquez López, F.; Stefan, C. Suitability Mapping for Managed Aquifer Recharge: Development of Web-Tools. Water 2019, 11, 2254. [CrossRef]

16. Ringleb, J.; Sallwey, J.; Stefan, C. Assessment of Managed Aquifer Recharge through Modeling-A Review. Water 2016, 8, 579. [CrossRef]

17. Sterman, J.D. Business Dynamics: System Thinking and Modelling for Complex World; McGraw-Hill: New York, NY, USA, 2000.

18. Qaiser, K.; Ahmad, S.; Johnson, W.; Batista, J.R. Evaluating water conservation and reuse policies using a dynamic water balance model. Environ. Manag. 2013, 51, 449-458. [CrossRef] [PubMed]

19. Wang, K.; Davies, E.G.R.; Liu, J. Integrated water resources management and modeling: A case study of Bow river basin, Canada. J. Clean. Prod. 2019, 240, 118242. [CrossRef]

20. Niazi, A.; Prasher, S.O.; Adamowski, J.; Gleeson, T. A system dynamics model to conserve arid region water resources through aquifer storage and recovery in Conjunction with a Dam. Water 2014, 6, 2300-2321. [CrossRef]

21. Clark, R.; Gonzalez, D.; Dillon, P.; Charles, S.; Cresswell, D.; Naumann, B. Reliability of water supply from stormwater harvesting and managed aquifer recharge with a brackish aquifer in an urbanising catchment and changing climate. Environ. Model. Softw. 2015, 72, 117-125. [CrossRef]

22. Gao, L.; Connor, J.D.; Dillon, P. The economics of groundwater replenishment for reliable urban water supply. Water 2014, 6, 1662-1670. [CrossRef]

23. Lindhe, A.; Rosén, L.; Norberg, T.; Bergstedt, O. Fault tree analysis for integrated and probabilistic risk analysis of drinking water systems. Water Res. 2009, 43, 1641-1653. [CrossRef] [PubMed]

24. WHO. Guidelines for Drinking-Water Quality; Fourth edition incorporating first addendum; World Health Organization: Geneva, Switzerland, 2017.

25. SMEC. Study of Open Water Evaporation in Botswana; Final Report; SMEC for DWA: Melbourne, Australia, 1987.

26. Wellfield Consulting Services \& CIC Energy. Mmamabula Energy Project. Bankable Feasibility Study; Kudumatse Groundwater Resources Report; Wellfield Consulting Services/CIC Energy: Gaborone, Botswana, 2007. 
27. Geo World. Masama Groundwater Resources Evaluation Project-Groundwater modelling; Final Report; Geo World: Gaborone, Botswana, 2009.

28. Water Resources Consultants. Post-Auditing of the Palla Road Groundwater Model (Palla Road E Chepete Wellfields); Draft Modelling Report; Water Resources Consultants: Gaborone, Botswana, 2012.

29. Water Resources Consultants. Post-Auditing of the Palla Road Groundwater Model (Palla Road E Chepete Wellfields); Final Modelling Report \& Wellfield Report; Water Resources Consultants: Gaborone, Botswana, 2013.

30. Geotechnical Consulting Services. Review of Monitoring Performed by DWA and DGS-Assessment of Water Resources and Improvement of Techniques; Geotechnical Consulting Services: Gaborone, Botswana, 2000.

31. Geotechnical Consulting Services. Kanye Emergency Works Water Supply Project; Final Report, Appendix 3 Groundwater Modelling; Geotechnical Consulting Services: Gaborone, Botswana, 2006.

32. Water Surveys Botswana. Costing of Botswana Water Supply and Demand Clusters Investigation; Water Surveys Botswana: Gaborone, Botswana, 2008.

33. Water Surveys Botswana. Gaotlhobogwe Wellfield Borehole Replacement Emergency Project; Final Report, Volume 1 Main Report \& Volume 3 Modelling; Water Surveys Botswana: Gaborone, Botswana, 2010.

(C) 2020 by the authors. Licensee MDPI, Basel, Switzerland. This article is an open access article distributed under the terms and conditions of the Creative Commons Attribution (CC BY) license (http://creativecommons.org/licenses/by/4.0/). 